\title{
O COMÉRCIO ELETRÔNICO SOB A ÓTICA GEOGRÁFICA
}

Pedro Eduardo Ribeiro de Toledo ${ }^{1}$

Resumo: Neste artigo, o comércio eletrônico é tomado como pauta para uma análise geográfica de sua estrutura e de diferentes aspectos. Dentre estes aspectos, apresentaremos alguns rascunhos teóricos sobre a influência desta atividade nas pequenas cidades. Para tanto, o texto contextualiza o surgimento dessa atividade no contexto dos novos cenários macroeconômicos, tendo como enfoque a tecnologia de informação e as mudanças na relação entre as empresas, ressaltando-se, assim, a análise das recentes transformações no âmbito da realização da mercadoria, configurada na forma do comércio, e sua logística espacial. A análise se apresenta mediante um paralelo entre os fatores que representam a mudança no comércio e sua relação com a indústria trazendo como pano de fundo nesta discussão uma leitura de alguns apontamentos de economistas políticos clássicos como Karl Marx e outros, de forma que o entendimento dessas mudanças pela ciência geográfica tenha como ponto de apoio sua dinâmica espacial. Nesta mesma ótica, o trabalho aponta caminhos epistemológicos para a interpretação geográfica do objeto de estudo.

Palavras-chave: Geografia Econômica. Comércio Varejista. Tecnologia de Informação. Comércio Eletrônico. Pequenas Cidades.

\section{ELECTRONIC TRADE UNDER GEOGRAPHICAL OPTICS}

Abstract: In this article, e-commerce is taken as a guide for geographic analysis of its structure and different aspects. Among these aspects, we will present some theoretical drafts on the influence of this activity in small cities. To do so, the text contextualizes the emergence of this activity in the context of the new macroeconomic scenarios, focusing on information technology and changes in the relationship between companies, thus highlighting the analysis of recent transformations in the scope of the realization of the merchandise, configured in the form of commerce, and its space logistics. The analysis is presented by a parallel between the factors that represent the change in the trade and its relation with the industry, bringing as a background in this discussion a reading of some notes of classic political economists like Karl Marx and others, so that the understanding of these geographical science has as its point of support its spatial dynamics. In this same perspective, the work points epistemological ways to the geographical interpretation of the object of study.

Keywords: Economic Geography. Retail Trade. Information Technology. Electronic Commerce. Small Cities.

\section{EL COMERCIO ELECTRÓNICO BAJO LA ÓSTICA GEOGRÁFICA}

Resumen: En este artículo, el comercio electrónico se toma como pauta para un análisis geográfico de su estructura y de diferentes aspectos. Entre estos aspectos, presentaremos algunos borradores teóricos sobre la influencia de esta actividad en las pequeñas ciudades. Para ello, el texto contextualiza el surgimiento de esa

\footnotetext{
${ }^{1}$ Universidade Federal de Uberlândia - UFU, Instituto de Geografia - IGUFU - Curso de Engenharia de Agrimensura e Cartográfica, Monte Carmelo/MG, Brasil, pertoledo@ufu.br, https://orcid.org/00000002-0553-6037
} 
actividad en el contexto de los nuevos escenarios macroeconómicos, teniendo como enfoque la tecnología de información y los cambios en la relación entre las empresas, resaltando así el análisis de las recientes transformaciones en el ámbito de la realización de la mercancía, configurada en la forma del comercio, y su logística espacial. El análisis se presenta mediante un paralelo entre los factores que representan el cambio en el comercio y su relación con la industria trayendo como telón de fondo en esta discusión una lectura de algunos apuntes de economistas políticos clásicos como Karl Marx y otros, de forma que el entendimiento de esas los cambios por la ciencia geográfica tengan como punto de apoyo su dinámica espacial. En esta misma óptica, el trabajo apunta caminos epistemológicos para la interpretación geográfica del objeto de estudio.

Palabras clave: Geografía Económica. Comercio al por menor. Tecnología de la Información. Comercio Electrónico. Pequeñas Ciudades.

\section{Introdução}

Uma retomada da história econômica brasileira nas últimas décadas permite reconhecer um processo de mudança na estrutura comercial baseada em transformações de ordem macroeconômicas. Tais mudanças vêm ocorrendo desde o início do século XX, no momento em que o capital produtivo já alcançava certa maturidade, pois vem se desenvolvendo desde o início do século XIX, e o mercado começa a ser impulsionado tanto para a realização da mercadoria, como no desenvolvimento de instrumentos para geração de demanda. No Brasil, houve significativas mudanças no cenário das estruturas comerciais, devido a diminuição dos oligopsônios nos anos 50, acompanhando uma tendência mundial.

No entanto, a busca por inovações técnicas, principalmente nas áreas de informática e de telecomunicações, motivadas pela crise do capitalismo dos anos da década de 1970, e marcada na história pela crise do petróleo, com consequências nas bases produtivas de maneira em geral. Sobre estas inovações técnicas não se podem dizer que a crise nesse modo de produzir, com destaque para o sistema toyotista e uma organização geral da sociedade com bases no fordismo², tenha levado ao seu fim. Mas podemos afirmar que tal crise, foi um dos principais pilares

\footnotetext{
${ }^{2}$ A conclusão geral a que cheguei e que, uma vez adquirida, serviu de fio condutor de meus estudos, pode formular-se resumidamente assim: na produção social de sua existência, os homens estabelecem relações determinadas, necessárias, independentes de sua vontade, relações de produção que correspondem a um determinado grau de desenvolvimento das forças produtivas materiais. O conjunto dessas relações de produção constitui a estrutura econômica da sociedade, a base concreta sobre a qual se eleva uma superestrutura jurídica e política à qual correspondem determinadas formas de consciência social. O modo de produção da vida material condiciona o desenvolvimento da vida social, política e intelectual em geral". (MARX, Karl. Prefácio a Contribuição à crítica da economia política. In BOTELHO, André (org) Essencial sociologia. São Paulo: Penguin Classics/Cia. Das Letras, 2013, p. 35)
} 
para a aceleração do processo de desenvolvimento do setor tecnológico, sobretudo nos Estados Unidos.

Subjacentes a esse processo havia duas vertentes centrais: investimentos na indústria de hardware e avanços no campo da comunicação, em especial nos recursos eletrônicos. No mesmo sentido do desenvolvimento do sistema capitalista, a pauta para o setor comercial era a criação de meios de criação de demanda, direcionamento e fidelização do consumo, de modo, que as grandes marcas se tornassem mundiais e atribuíssem um status social ao indivíduo, não importando se o consumidor estivesse localizado em uma grande, ou pequena cidade.

Tais avanços remontam ao início da Guerra Fria, isto é, a pesquisas feitas pelo setor militar norte-americano que resultaram na criação de uma rede local de computadores que culminou no desenvolvimento da rede mundial de computadores - a internet.

Dito isso, este artigo objetiva analisar o cenário do comércio eletrônico no contexto das transformações macroeconômicas. Apresentamos sua estrutura e como a nova tecnologia de informação dinamiza a relação de comércio da sociedade com as empresas e das empresas entre si. Essa apresentação inclui um quadro introdutório sobre o comércio eletrônico e suas faces, assim como uma análise do contexto teórico, de modo a estabelecer sua relação com a ciência geográfica. Como forma de entender a abordagem que damos à referida temática, oferecemos uma visão geral do desenvolvimento da internet em seu período de evolução dos meios de comunicação e sua incorporação para o mundo dos negócios.

Enquanto campo metodológico, esta pesquisa se baseia no Materialismo Histórico e Dialético, e faz uso de uma leitura teórica sobre os conceitos que embasam tanto a perspectiva da Economia Política e da Ciência Geográfica, além do uso de dados secundários e primários que dão suporte aos caminhos teóricos.

Como forma de leitura geográfica dessa temática, podemos dizer que esse processo traz uma grande dinâmica espacial através de construção e rearranjo dos fixos e do grande volume de fluxos no entendimento de adequação produtiva e de mercado na ordem macroeconômica - logo, no entendimento dessa dinâmica de ordem geográfica, onde ao longo do processo de desenvolvimento e melhoria das redes de comunicação, os pequenos municípios foram inseridos no atual cenário de reprodução do sistema capitalista, através de suprimento da demanda de consumo por meio do comércio eletrônico (onde as lojas físicas localizadas nestes pequenos 
municípios não conseguem suprir a demanda de consumo que cada vez mais se apresenta como global). Assim, as tecnologias no setor de automação, que engloba meios de comunicação, é o que dá unidade a esse processo. O espaço organizouse e modelou-se para dinamizar o próprio fluxo de matéria-prima, produção e mercadorias pela matriz industrial desenvolvida, nessa nova perspectiva. A infraestrutura presente no mesmo espaço se torna passível de revisões conceituais sobre a materialização dos objetos e equipamentos dessa nova ordem, sendo possível, como já ressaltado, estabelecer o papel do comércio eletrônico, enquanto meio de reprodução do sistema capitalista, nas grandes, médias e pequenas cidades.

Inicialmente, este artigo apresentará à relação entre a concepção do comércio eletrônico enquanto derivado do processo de inovação das tecnologias de computação e de comunicação, e sua relação e enquadramento dentro das transformações econômicas de maneira em geral. A seguir, será analisado os dados do perfil do consumidor brasileiro, de forma que possamos estabelecer relações com o campo espacial, no prospecto das pequenas e médias cidades. Para finalizar, será estabelecida o campo de relação da atividade do comércio eletrônico com a ciência geográfica, de forma que possamos fechar este artigo com as considerações finais a despeito das conclusões dos autores e o apontamento de caminhos investigativos para a geografia com relação a esta temática.

\section{Comércio eletrônico: nova perspectiva de negócios para a reprodução capitalista}

O comércio eletrônico como fruto do desenvolvimento dos setores de hardware e telecomunicações se apresenta como inovação nesse processo de expansão e diversificação dos estabelecimentos comerciais, na relação entre estes e o setor atacadista e pelas empresas, que passam a realizar investimentos em centros de distribuição de pequeno, médio e grande porte para cumprir seu papel logístico. Além disso, o setor de serviços tem apresentado grandes investimentos em portais eletrônicos para divulgação e contratação de suas atividades. Dentre os vários segmentos desse setor, podemos dar destaque os bancos, que nos últimos anos têm realizado grandes investimentos no processo de interação de seus clientes com seus serviços através de websites - também denominadas portais eletrônicos —, como apresenta o estudo de Magalhães (2007). Outra perspectiva de estudos 
sobre as influências que as tecnologias de informação (TI) geraram para o mercado consumidor está ligada a este mercado na ótica do consumo, conforme aponta Nakagawa (2008, p. 27-28):

\begin{abstract}
Diversos modelos de negócios surgem em tempos de crise como uma resposta às mudanças ambientais e aos desafios que a nova realidade impõe. Muitas vezes, estes modelos são apoiados por avanços em tecnologia e acesso crescente à informação. Vavra (1992), ao analisar um passado não tão longínquo, lembra que, nos anos 80 , a estrutura de mercado tornou-se mais complexa, o mercado consumidor fracionou-se e as ofertas de produtos proliferaram. Paralelamente a tecnologia computacional experimentava melhorias em custos capacidade de armazenamento, oferecendo subsídios para que as empresas conhecessem melhor os seus clientes. A década de 90 assistiu, maravilhada, a uma mudança de comportamento de mercados e dos consumidores que antes não se imaginava. A chamada globalização rompeu fronteiras, derrubou mitos e permitiu uma fabulosa interação cultural entre as nações. A informação deixou de ser um recurso escasso entre os concorrentes: capacidades de pesquisa extensivas faziam parte da estratégia da maioria deles.
\end{abstract}

No âmbito da administração, a mudança no paradigma de produção, dentre outras origens, tem raízes no "desenrolar" de uma mudança ocorrida no Japão após os anos 50 que se vinculou à recuperação econômica desse país após a Segunda Guerra Mundial. Uma mudança central ocorreu na administração da produção, motivada, em especial, por transformações na indústria automotiva Toyota. Conhecida como "toytismo", tal mudança chegou ao ocidente com o nome de produção flexível ou pós-fordismo. Na organização toyotista do processo de trabalho, que veio historicamente substituir a organização taylorista, o processo de administração da produção apresenta estas finalidades principais: a produção destinada a suprir diretamente a demanda social - que, ao contrário da linha fordista, não cria estoques; a não especialização da produção - destinada não a um produto apenas, mas a um nicho, o que criou possibilidades para que as empresas "encolhessem" ou ampliassem seu escopo conforme sua situação no mercado; enfim, o conceito de just-in-time - derivação desse processo que supõe obter mais eficiência na produção e na realização da mercadoria para a sociedade. Esta perspectiva pode ser representada pela existência dos E-marketplaces no âmbito virtual que agrega e consolida negócios de diversos produtores de um mesmo escopo de produtos, e que estão espalhados por todo território nacional ou mesmo fora do país, aonde a parte física ( Hardware e Software) está localizada nas grandes cidades e a produção espalhada no empreendedorismo individual nas grandes, médias e pequenas cidades. 
Nesse sentido, os investimentos no setor de tecnologia da informação diversificaram os modos de comunicação, acelerando o acesso da sociedade a esse campo tecnológico e ao mercado após o surgimento da internet. Esse cenário se expandiu no Brasil a partir do segundo lustro dos anos de 1990 e avançou com rapidez em nossa sociedade, porém encontrou dificuldades técnicas no início deste processo, como destaca Carvalho (2006, pág. 143):

A Internet comercial no Brasil chegou ao ano de 1996 com uma infraestrutura insuficiente para atender à demanda dos novos provedores de acesso comercial e, principalmente, dos seus usuários. Com a saída da Embratel do mercado de provimento de acesso para pessoas físicas e a RNP ainda se estruturando para permitir o acesso dos novos provedores comerciais ao seu backbone, muitos usuários no Brasil ficaram sem ter como se conectar à Internet. $\mathrm{E}$ mesmo que alguns provedores conseguissem acesso a algum backbone Internet e a respectiva rede de suporte para a transmissão de dados, não havia linhas telefônicas disponíveis para atender às chamadas dos (computadores de) seus clientes. Era comum provedores precisarem de dezenas ou mesmo centenas de números telefônicos de uma só vez, o que fazia com que alguns provedores colocassem até duzentos usuários na disputa por uma mesma linha de acesso.

O Acesso à tecnologia e o desenvolvimento dos sistemas de comunicação ainda são contestados por muitos teóricos, para os quais essa tecnologia ainda está vinculada a grupos de média e alta renda. Mas a perspectiva, criada pelos japoneses, de substituição precoce de tecnologias e o auxílio ao consumo em massa, facilitados pela potente ação do capitalismo financeiro, conduzem-nos ao entendimento de que essas tecnologias, no setor de automação e informação, vêm se popularizando cada vez mais rapidamente e serão, num futuro próximo, bases possíveis para retomar investimentos ligados à nova fase expansiva dos ciclos de que fala Kondratieff. ${ }^{3}$

O comércio eletrônico encontra-se em plena fase de expansão, mas sua realidade ainda não se apresentou com tanta veemência nos países da periferia do sistema, graças, sobretudo, ao acesso parco da população ao computador (perspectiva esta que inicia sua mudança através do incentivo constante do Estado em sua política de inclusão e educação digital). Nas pequenas cidades este fator se apresenta com maior veemência, pois estes municípios ainda encontram dificuldades de realização de vendas e compras no âmbito do comercio eletrônico,

\footnotetext{
${ }^{3}$ Nikolai Dimitrievich Kondratieff - Николай Дмитриевич Кондратьев, em alfabeto cirílico nasceu em Goloejevskaja, a 4 de março de 1892, e morreu em Suzdal, a 17 de setembro de 1938. Foi um economista russo e um dos teóricos da NEP; é mais conhecido, porém, por ter sido o primeiro a tentar provar, estatisticamente, o fenômeno das "ondas longas", dos movimentos cíclicos (ciclo econômico) de aproximadamente 50 anos de duração e que ficaram conhecidos na economia como ciclos de Kondratieff.
} 
dado à precariedade das redes de internet, tanto por cabo, como por sistema sem fio. Cabe lembrar que o telefone móvel demorou apenas alguns anos para se popularizar de forma expressiva, ao contrário de alguns elementos tecnológicos como televisor e geladeira, que demoraram mais de uma década para atingir mais de 50 milhões de usuários. A internet, por sua vez, precisou de dois anos para atingir essa cifra, apesar desta discrepância em termos de disposição no território brasileiro.

Aqui, o e-business e o e-commerce são o principal foco de interesse de pesquisa em razão de sua ligação direta com a reengenharia produtiva e articulação espacial das empresas. A consolidação de uma grande empresa significa se consolidar para a sociedade como um todo de sua identidade denominada "marca": elemento fundamental para realizar compras on-line, pois define o nível de confiabilidade do consumidor na mercadoria oferecida. Assim, a recente transformação no âmbito macroeconômico brasileiro no que se refere à reestruturação empresarial apresenta um campo amplo de estudo dessa dinâmica, entendida e desmistificada pela leitura dos campos que compreendem essa ordem macroeconômica. O estudo dessa reestruturação empresarial e o entendimento de sua dinâmica espacial são fundamentais para a ordem epistemológica da ciência geográfica porque trabalha e revisa seus conceitos diretamente e em diferentes escalas, como é o caso da análise desta atividade nas pequenas cidades. O diálogo estabelecido por este trabalho entre a economia política e geografia torna-se complementar a essa perspectiva. As análises e a diversidade de faces que poderiam ser abordadas na relação do comércio eletrônico para com as pequenas cidades seriam infinitas se fossemos aponta-las caso a caso neste estudo, que buscou apresentar uma explanação geral sobre uma leitura possível da atividade de comércio eletrônico para as pequenas cidades e a geografia de modo em geral.

Mas essa nova perspectiva nos remete a uma revisão conceitual da ciência que trata da organização espacial sobre a materialização dos objetos e equipamentos presentes no espaço na nova era digital. A escolha por este tema se deu, principalmente, pelo desafio de trabalhar na perspectiva de uma nova forma de negócio que nos conduz a uma espacialidade insólita pela falta de materialização de objetos no espaço pelas empresas e a perspectiva de um consumo globalizado, principalmente para o consumidor localizado nas pequenas cidades. Estas criam sua estrutura com baixo estoque de capital, porém não só influenciam a dinâmica do 
comércio e a reestruturação empresarial - que engloba a produção; também trabalham com o espaço geográfico como se este fosse um tabuleiro de xadrez onde a organização das peças (objetos/cadeia produtiva) é a base para os movimentos que conduzirão à vitória (fluxos/realização no mercado).

Os altos índices de crescimento dos centros urbanos, que trazem suas intempéries, e a baixa oferta de produtos e serviços nas pequenas cidades geraram uma demanda de facilidades e ofertas de produtos, criando espaço para o nascimento e crescimento dos negócios realizados por meios digitais, conforme veremos ao longo deste trabalho. Nesse sentido, as duas principais perguntas a serem respondidas para a ciência geográfica são: o comércio eletrônico é capaz de modificar o processo de formatação espacial já atribuído à dinâmica da velha economia? O comércio eletrônico simplesmente eliminou algumas estruturas físicas do comércio tradicional ou criou uma "espacialidade" paralela no mundo digital?

Assim, como um dos apontamentos na análise teórica sobre o referido assunto, nessa transformação do paradigma comercial até então, em muitos casos a empresa realiza a venda do produto (uma fotografia no website) sem tê-lo produzido; fato este que exerce certa pressão do comércio sobre a indústria e cria caminhos alternativos e virtuais no circuito do capital, à luz da teoria de Karl Marx.

Em continuidade da apresentação dos dados que demonstram o crescimento da internet, o grande desenvolvimento do setor de comunicações através das constantes melhorias nos sistemas já existentes e com o advento da internet que se "populariza" em larga escala (Tabela 01) no Brasil nos anos 90 está mudando o modo de efetivar a compra dos mais diversos produtos.

Tabela 01- Dados sobre uso da internet no Brasil: crescimento percentual (set. de 1997nov. 2018)

\begin{tabular}{ccccc}
\hline $\begin{array}{c}\text { ANO DA } \\
\text { PESQUISA }\end{array}$ & $\begin{array}{c}\text { POPULAÇÃO } \\
\text { TOTAL } \\
\text { (MILHÕES) }\end{array}$ & $\begin{array}{c}\text { INTERNAUTA } \\
\text { (MILHÕES) }\end{array}$ & $\begin{array}{c}\text { \% DA } \\
\text { POPULAÇÃO }\end{array}$ & $\begin{array}{c}\text { FONTE DA PESQUISA } \\
\text { INTERNAUTAS }\end{array}$ \\
\hline 2018/nov. & 209,0 & 116 & $56,6 \%$ & IBGE \\
2015/set. & 204,9 & 106,6 & $51,6 \%$ & Banco Mundial \\
2011 & 203,4 & 70,18 & $45,7 \%$ & Banco Mundial \\
2006/dez. & 188,6 & 51,96 & $28,2 \%$ & Internet WorldStats \\
2005/jan. & 185,6 & 25,90 & $13,9 \%$ & Internet WorldStats \\
2004/jan. & 178,4 & 20,05 & $11,5 \%$ & Nielsen NetRatings \\
2003/jan. & 176,0 & 14,32 & $8,1 \%$ & Nielsen NetRatings \\
2002/ago. & 175,0 & 13,98 & $7,9 \%$ & Nielsen NetRatings \\
\hline
\end{tabular}




\begin{tabular}{llllc}
\hline 2001/set. & 172,3 & 12,04 & $7,0 \%$ & Nielsen NetRatings \\
2000/nov. & 169,7 & 9,84 & $7,1 \%$ & Nielsen NetRatings \\
1999/dez. & 166,4 & 6,79 & $5,8 \%$ & Computer Ind. Almanac \\
1998/dez. & 163,2 & 2,35 & $1,4 \%$ & IDC \\
1997/dez. & 160,1 & 1,30 & $0.8 \%$ & Brazilian ISC \\
1997/dez. & 160,1 & 1,15 & $0,7 \%$ & Brazilian ISC \\
\hline
\end{tabular}

Fonte: CÂMARA BRASILEIRA COMÉRCIO ELETRÔNICO/CBCE, 2019.

Nesse contexto, podemos considerar que a internet nasce do casamento entre a evolução dos sistemas de comunicação e a evolução do setor de informática. Ambos receberam investimentos maciços após a entrada no período recessivo da economia que se iniciou com a crise do petróleo de 1973 (RANGEL, 2005). Esse autor destaca tal evolução nos sistemas como forma de retomar o crescimento por países do centro do sistema, sobretudo Estados Unidos, que já haviam lançado investimentos nesse setor durante a Segunda Guerra Mundial através de empresas como a IBM.

A entrada da IBM no mercado de computadores pessoais (PC), em 1981, foi de grande importância para a legitimidade e a credibilidade do nascente setor. Dois anos após o lançamento do PC, a IBM detinha 75\% do mercado, que continuava a crescer. Em 1984, havia 19 milhões de PC's em uso nos Estados Unidos, distribuídos em partes iguais entre lares e empresas. Embora a IBM ultrapassasse rapidamente as vendas da Apple, esta continuava a construir um segmento fiel e lançar inovações destinadas a simplificar a operação do PC. (MAYO; NOHRIA, 2008, p. 20).

A tecnologia de informação possibilitou conhecer mais as tendências de consumo da sociedade, em especial o fato de que o acesso da sociedade ao mercado se tornou mais próximo e dinâmico. Peter Drucker (2001), analista da administração empresarial que acumulou larga experiência trabalhando como consultor de empresas como General Motors e outras, faz certos apontamentos sobre o comércio eletrônico que se mostram convenientes a este estudo. Diz ele:

O comércio eletrônico é para a revolução da informação o que a ferrovia foi para a Revolução Industrial - um avanço totalmente novo, totalmente sem precedentes, totalmente inesperado. Fazendo uma analogia com a ferrovia de 170 anos atrás, o comércio eletrônico está criando uma nova explosão, mudando rapidamente a economia, a sociedade e a política. (DRUCKER, 2001, p. 92).

Com efeito, vivenciamos um segundo momento desse padrão de consumo. A análise mercadológica já tem como preceito que a tecnologia de informação está sendo cada vez mais difundida na sociedade, passa a explorar os métodos e a 
metodologia de venda via meio digital e a analisar o padrão de consumo dentre os produtos oferecidos na grande rede. Para a geografia, esse ponto se torna fundamental em sua análise espacial, pois, após anos de exploração da espacialidade do comércio na cidade, temos a plena certeza da localização dos pontos comerciais, mas não a do consumidor, que, graças à tecnologia, pode estar localizado em qualquer parte do mundo. Esta lógica se complementa e se torna mais interessante à análise pelo ponto de vista do consumidor, que mantém uma relação mais virtual com o ponto comercial do que geográfica; ou seja, o endereço da loja passa ser o eletrônico, e não mais o de sua representação física. Para tanto, encontramos a relação estabelecida entre produção, distribuição, troca e consumo, em sua análise conjuntural sobre o sistema capitalista conforme (MARX, 2003, p. 242);

A produção dá os objetos que correspondem às necessidades; a distribuição os reparte de acordo com as leis sociais; a troca reparte de novo o que já está distribuído segundo a necessidade individual; e, finalmente no consumo, o produto desaparece do movimento social, convertendo-se diretamente em objeto e servidor da necessidade individual e satisfazendo-a com disfrute. A produção aparece assim como o ponto inicial; o consumo como ponto final; a distribuição e a troca como o centro, que por isso mesmo é dúplice, já que a distribuição é determinada como emana dos indivíduos.

A compra pela internet se dá através de uma página eletrônica (website) criada pela empresa que apresenta, através de fotografias, textos e vídeos, produtos e informações organizados por setor. A maioria das páginas eletrônicas contém uma ferramenta de busca de produtos que facilita e dinamiza o processo de compra. Quando o consumidor escolhe o/s produto/s desejado/s por meio de sua seleção, a página gera um boleto - ou links - para que ele informe seus dados do cartão magnético, a fim de que a compra seja efetivada. Feito isso, a informação é enviada automaticamente a uma central e, logo, ao centro de distribuição, que cuidará do envio. Para o consumidor, essa página eletrônica pode ser acessada em qualquer parte do globo; mas os centros de distribuição ou locais para retirada de produto estão localizados no espaço e impõem à empresa a necessidade de entregá-los de forma tão rápida quanto sua aquisição, para que esse instrumento de compra crie uma gama cada vez maior de usuários.

Nessa lógica, a logística espacial para as empresas - grandes e pequenas - torna-se determinante central de seu sucesso no mercado, tanto na captação de matérias-primas quanto na organização da produção, no gerenciamento da 
produção e do comércio e na realização da mercadoria para a sociedade. Desse modo, para a ciência geográfica, a análise pode ser realizada não só nos condicionantes logísticos, formadores deste espaço, mas também nas influências diretas na materialização de aspectos sociais e econômicos trabalhados por autores da geografia econômica e na receptividade dessa tecnologia pelo comportamento de consumo da sociedade, como trabalhado por autores que enfatizam mais a linha sociológica, a exemplo de Manuel Castells (2003).

Outro fator importante nessa análise se refere à revisão de conceitos que fundamentam a ciência geográfica, tais como espaço, tempo e territorialidade dessas corporações.

As redes já mudaram o modo de comunicação nos Estados Unidos. Todos os dias ocorrem milhões de negócios entre dezenas de milhares de conexões em alta velocidade, através de computadores espalhados por todo o mundo. Em apenas alguns segundos, transmitem-se centenas de páginas pelos Estados Unidos. Solicitações alcançam a Inglaterra, Japão ou Austrália com um rápido movimento de tela do computador, e respostas chegam antes que uma chamada telefônica ou transmissão por fax seja concluída. Os programas armazenados em mainframe na Califórnia podem ser descarregados instantaneamente em um desktop em Nova York, usando apenas alguns comandos simples. Pesquisadores de Universidades e laboratórios corporativos de desenvolvimento, que nunca se encontram pessoalmente, colaboram em base on-line para desenvolver e testar novos produtos, economizando meses, ou mesmo anos no processo. (CRONIN, 1995, p. 1).

O número crescente de websites, fato esse que denota não somente a democratização da tecnologia, mas também - e, sobretudo - o crescente investimento em propaganda e negócios realizados pela via eletrônica. No entanto - cabe frisar - , a tecnologia de informação mostrou-se, em um primeiro momento, como novidade restrita a alguns grupos, como aconteceu também com a tecnologia de telefonia móvel. Os grupos de alta renda e a classe média alta tornam-se, dessa maneira, consumidores de novidades nesse ramo de novidades. Para o comércio eletrônico, é importante ser destacado que, embora as páginas eletrônicas sejam disponibilizadas para todo o mundo, existe o condicionante do consumo que é limitado pela língua; nesse caso, o pós-fixo ".com.br" delimita a regionalização brasileira das empresas no mundo virtual; esse exemplo pode ser usado para o mundo todo. Nesse sentido, o comércio eletrônico e outras formas de uso da internet são realizados, na maioria dos casos, de forma regional para os brasileiros, que usam as páginas eletrônicas nacionais para compras ou lazer. 
É nesse espaço cuja lógica de construção e cujas dinâmicas se diferenciam das do espaço geográfico tradicional que vemos margem para análises geográficas; isto é, nessa lógica vemos um espaço para aplicar conceitos da geografia. Esse espaço paralelo e virtual cuja existência é movida pelo e-commerce e pelo ebusiness denominamos aqui de "e-espaço". Assim, na proposta deste trabalho, o "eespaço" se torna uma proposta de conceito geográfico quando nos referimos à análise das espacialidades criadas no mundo virtual. Tal perspectiva, em nossa leitura, está focada na dinâmica econômica, mas pode ser realizada por outros prismas.

Feita essa retomada do nascimento da internet, das raízes de sua incorporação para finalidade econômica e de seu primeiro paralelo com a ciência geográfica, analisaremos a seguir o comércio eletrônico em sua face teórica para traçar novos paralelos com a geografia.

\section{O Perfil do consumidor brasileiro e a perspectiva para as pequenas cidades.}

Ao analisarmos a atividade comercial nos termos conceituais da ciência geográfica, podemos associá-la, principalmente, ao que tange à construção do espaço geográfico. Deste modo, como o percorrer da história econômica do século XX, período este posterior as ideias de Karl Marx o aumento da concorrência no setor produtivo, mas principalmente no setor comercial, conduziu as grandes corporações a investirem em constantes estratégias de domínio de mercado, e melhorias no setor logístico das cadeias de valor formada por diversas empresas. No entanto, ainda dentro desta perspectiva percebe-se que o setor comercial, tanto na relação entre empresas, ou com os consumidores, vem se destacando frente ao setor produtivo.

Segundo dados do E-Bit, portal eletrônico do Grupo Buscapé, que avalia e gera dados censitários de consumo e grau de satisfação dos consumidores na internet, apesar da queda do índice da variação no aumento do consumo por meio do comércio eletrônico pelos seguintes dados: Variação de 2012 para 2013 (28\%), 2013 para 2014 (24\%) e de 2014 para 2015 (15\%), o comércio eletrônico mostrou uma alta em seu faturamento: 2013 (28,8 Bilhões de reais), 2014 (35,8 Bilhões de reais) e em 2015 (41,3 Bilhões de reais), sendo que o incremento no número de econsumidores ativos diminuiu significativamente nos índices de variação de 2013 para 2014, onde passamos de cerca de 31 milhões para 38 milhões, com relação à 
variação de 2014 para 2015 onde foi acrescido um pouco mais de 1 milhão de econsumidores, e chegamos ao número final de 39.141 .590 de e-consumidores em 2015.

Outro dado importante a ser destacado nos dados da atividade de comércio eletrônico no Brasil, é o crescente aumento do consumo realizado por meio de equipamentos eletrônicos denominados de mobile (Tablets e Smartphones), onde saímos de uma taxa de $0,0 \%$ em janeiro de 2010 para 9,7\% em janeiro de 2015, dado este em que podemos analisar os "gargalos" infra estruturais que ainda ocorrem no setor privatizado do setor de telecomunicações, onde apesar do aumento significativo do índice, o consumidor ainda encontra dificuldades de realizar compras e consultas comparativas por meio dos mobiles nas pequenas cidades pela falta de uma rede $3 G$ nestes municípios, como é o caso empírico do município de Monte Carmelo, localizado na região de planejamento do Alto Paranaíba em Minas Gerais, que possuí em população estimada em 47.937 habitantes em 2015, segundo dados do IBGE, e que não possuí em rede 3G em sua malha urbana por conta da má administração das operadoras de telefonia presentes na cidade, enquanto que no município de Romaria, localizado na mesma região de planejamento do estado, com a população estimada em 2015 de 3.657 habitantes, segundo dados do IBGE, e possuí uma rede $3 G$.

Segundo dados estatísticos da Empresa E-bit por meio do Relatório Webshoppers sobre o panorama geral do Comércio Eletrônico em 2018:

\footnotetext{
Mesmo em um ano turbulento, com eventos como a Copa do Mundo, eleições, alta do dólar e os impactos da Greve dos Caminhoneiros, o comércio eletrônico brasileiro manteve a curva de crescimento em 2018 e registrou faturamento de $\mathrm{R} \$ 53,2$ bilhões, alta nominal de $12 \%$, comparado a 2017. Já são 58 milhões de consumidores online, ou seja, $27 \%$ da população brasileira, o que representa um crescimento de $6 \%$ em relação ao ano anterior. O setor é fomentado, principalmente, pelo crescimento no número de pedidos, que, em 2018, alcançou a marca de 123 milhões, e o ticket médio de compras foi de $\mathrm{R} \$ 434$, alta de $1 \%$.
}

Outro dado a ser destacado no perfil do Comércio Eletrônico no Brasil em 2018 é o aumento no número de pedidos realizados, apesar do decréscimo da variação nos últimos anos, conforme (Figura 01) a seguir: 
Figura 01- Brasil: Taxas de Aumento de Compras realizadas por meio do uso de Smartphones

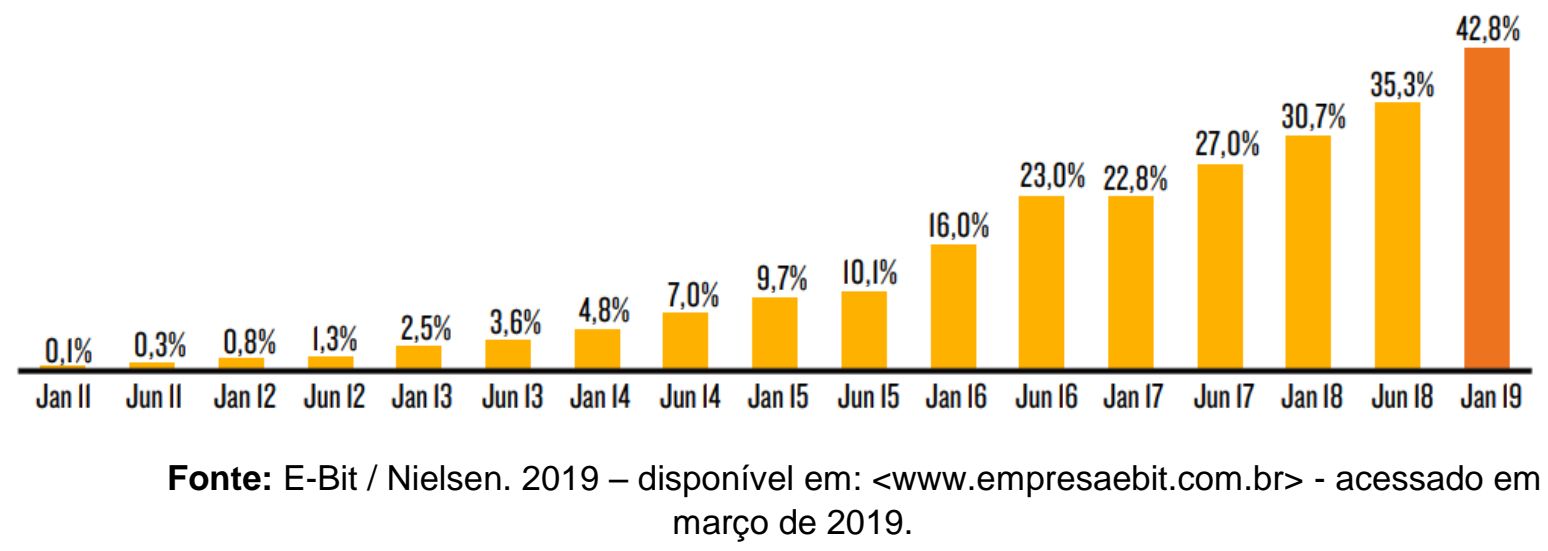

Dentre as categorias mais pedidas e consumidas por meio do comércio eletrônico em 2018, podemos destacar o aumento no volume de compras no setor de perfumaria e cosméticos, conforme dados apresentados na (Figura 02) a seguir:

Figura 02- Brasil: Categorias mais vendidas em 2018 em volume de pedidos

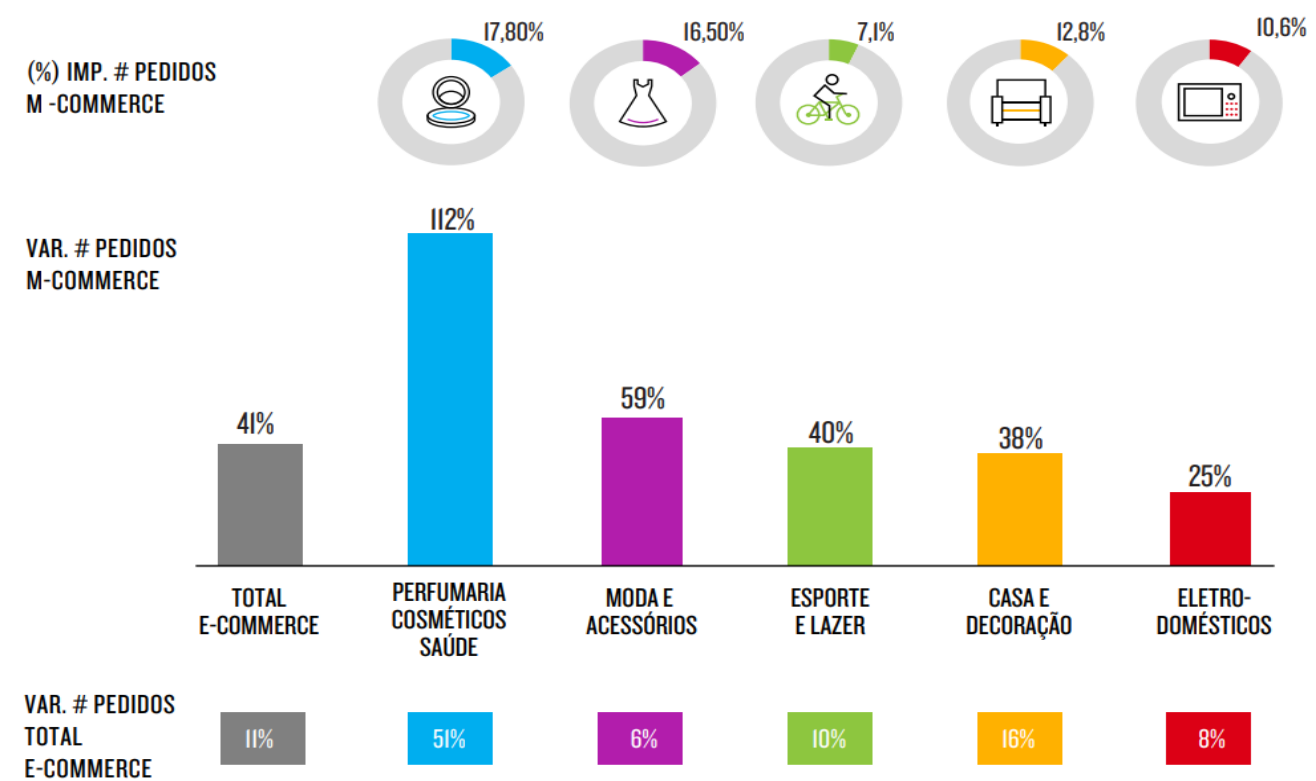

Fonte: E-Bit / Nielsen. 2019 - disponível em: <www.empresaebit.com.br> - acessado em março de 2019.

Com relação aos dados apresentados anteriormente na Figura 2, podemos destacar o aumento na variação das categorias de consumo pela internet, uma vez que no início da história do consumo pela internet no Brasil, os principais produtos consumidos e negociados eram apenas livros e CD's, pelo fato do consumidor ainda estar experimentando e adquirindo confiança nesta nova ferramenta e 
automaticamente não produzindo um ticket alto (valor do produto) por este meio, conforme (Figura 03) a seguir:

Figura 03- Brasil: Variação do Tíquete Médio nos últimos anos

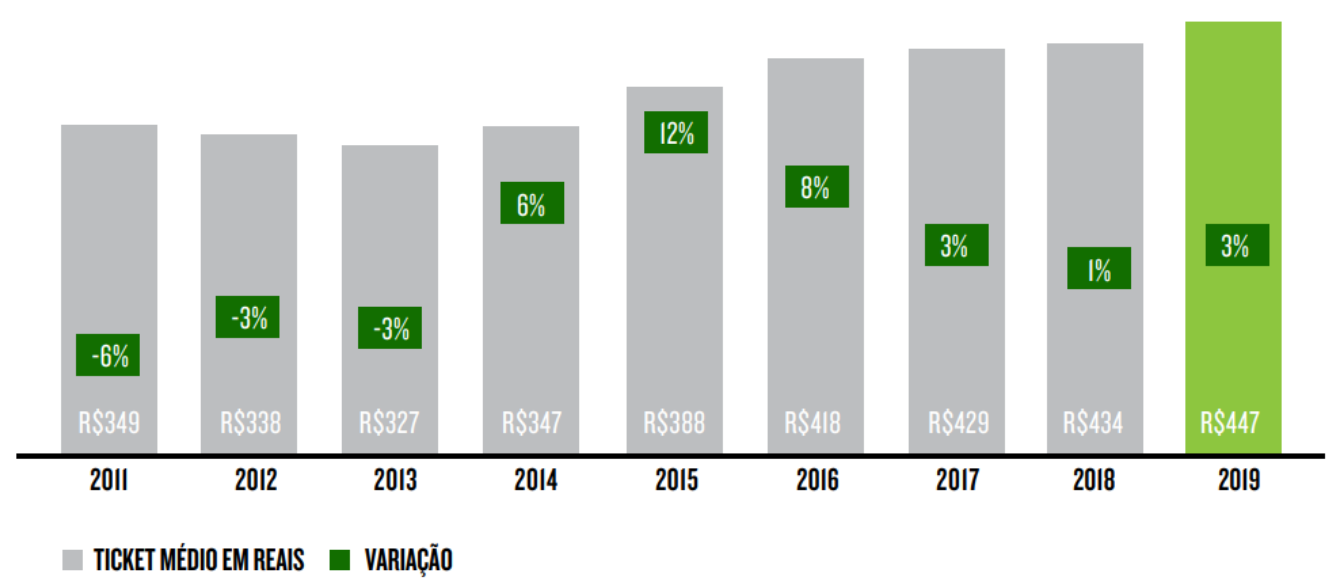

Fonte: E-Bit / Nielsen. 2019 - disponível em: <www.empresaebit.com.br> - acessado em março de 2019.

Hoje, com a difusão da tecnologia de comunicação, apesar dos gargalos infra estruturais, e o barateamento dos aparelhos eletrônicos pela lógica toyotista de envelhecimento precoce, o volume de compras pela internet aumentou, assim como também houve um aumento relativo do ticket médio e uma abordagem maior no escopo dos produtos adquiridos por este meio, conforme apresentado na Figura 3.

Deste modo, a pequena cidade contextualizou-se neste enredo econômico, não apenas pela inserção de novos e-consumidores que buscam suprir suas necessidades de consumo globalizadas, superando assim a oferta local, pela demanda global, mas também criando a oportunidade para os pequenos e médios negócios já presentes nestas cidades, disponibilizarem seus produtos e serviços por meio da internet, fazendo que arranjos produtivos locais, se tornassem globais.

O crescimento dos negócios realizados pela internet criou a oportunidade de novas economias que se agregam e dão suporte para o crescente usufruto do comércio eletrônico nas pequenas cidades. Além de o comércio físico buscar sua inserção no comércio por meio virtual, ainda foram criados portais eletrônicos de vendas diretas ao consumidor ${ }^{4}$ ou os denominados marketplaces que caracterizam enquanto portais eletrônicos que estabelecem o diálogo entre consumidores e

\footnotetext{
${ }^{4}$ Fato este que não substituí a demanda por estruturas físicas, pois apesar da loja ser virtual, há a necessidade da presença de depósitos e outros locais para preparar as mercadorias vendidas para serem despachadas.
} 
pequenas comércios que disponibilizam seus produtos para a venda através da internet.

\section{O comércio eletrônico e a abordagem geográfica}

As novas tecnologias de comunicação dadas pela internet, à criação do comércio eletrônico e o crescente número de usuários vêm trazendo, para o setor logístico das empresas, uma crescente demanda de melhorias e agilidade de seus respectivos setores logísticos. Essa busca na excelência logística fez que o mercado avaliasse melhor aquelas empresas que têm uma melhor conjuntura logística de seus fornecedores e uma melhor logística para entrega e inserção de seus produtos no mercado, e esta estrutura logística conecta as pequenas cidades aos grandes centros urbanos. A (Figura 04) a seguir representa esse cenário criado entre 0 recebimento de "insumos" para o setor produtivo - representado pela relação comercial entre as empresas e seus fornecedores através do B2B (business-tobusiness) - a relação entre os comerciantes e o mercado consumidor através do B2C (business-to-consumer) e a relação comercial entre pessoas físicas através do C2C (consumer-to-consumer).

Figura 04- Logística e Tipos de comércio eletrônico

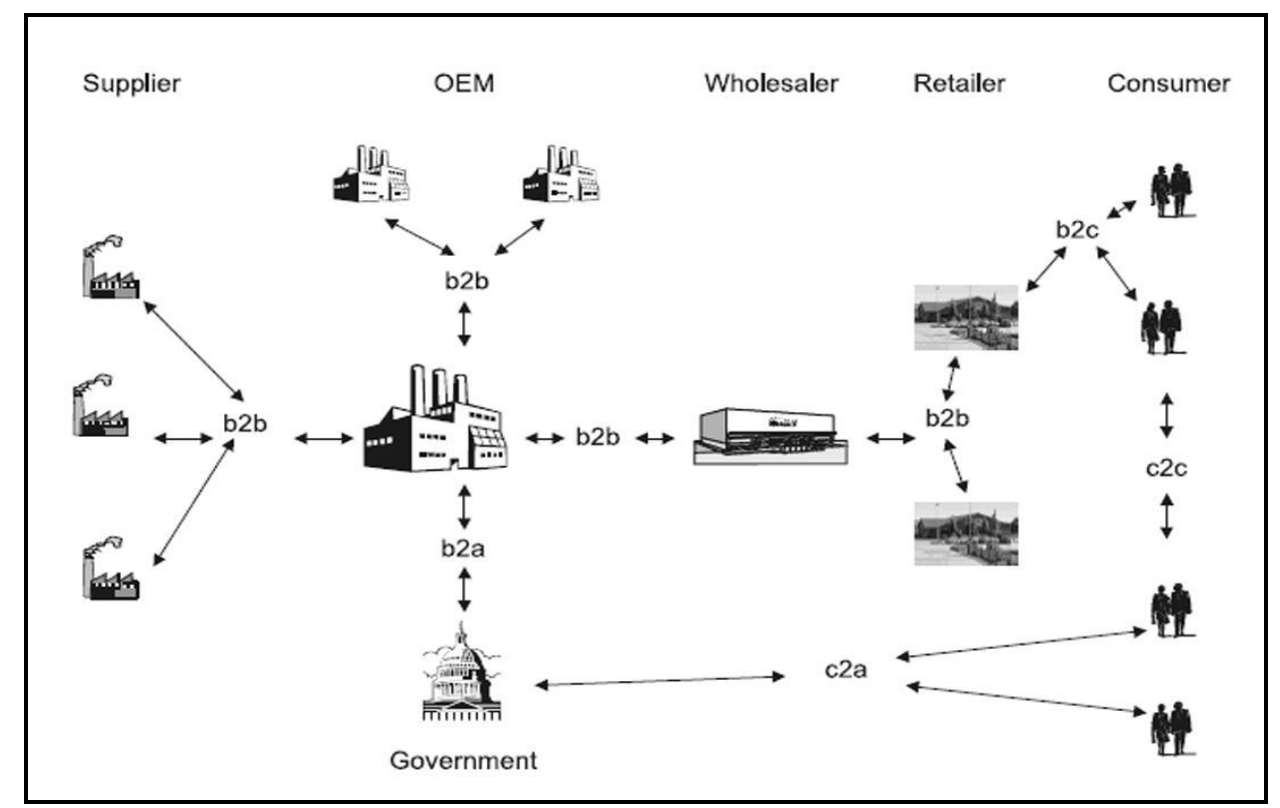

Fonte: TEZZA et al., 2008, p. 4.

O volume de movimentação de mercadorias pela internet, apesar se seus crescentes índices, ainda representa uma pequena parcela do varejo como um todo, no entanto, faz com que os comércios existentes, principalmente nas pequenas 
cidades, busquem acompanhar esta nova tendência de mercado. A Tecnologia de comunicação auxiliou o contato entre consumidores e os pequenos negócios existentes nos municípios de menor porte, seja por meio das páginas eletrônicas que realizam concretização das vendas, ou a simples divulgação dos produtos existentes na loja física. Esta nova perspectiva abriu campo para empresas ligadas ao desenvolvimento de páginas (sites) e demais estruturas na internet.

Manuel Castells faz considerações importantes sobre o uso da tecnologia da internet no setor produtivo e empresarial.

A internet está transformando a prática das empresas em relação com seus fornecedores e compradores, em sua administração, em seu processo de produção e em cooperação com outras firmas, em seu financiamento e na avaliação de ações em mercados financeiros. Os usos adequados da internet tornaram-se uma fonte decisiva da produtividade e competitividade para negócios de todos os tipos. (CASTELLS, 2003, p. 56).

$\mathrm{Na}$ análise geográfica, Milton Santos faz uma explanação sobre a influência da inovação tecnológica no espaço de maneira em geral. Segundo ele, a inovação tecnológica criou uma série de objetos no espaço, agilizando o fluxo de mercadorias e informações que dão base à consolidação do capitalismo; sobretudo, criou um meio que ele denominou de técnico-científico-informacional, para o qual "O espaço torna-se fluído, permitindo que os fatores de produção, o trabalho, os produtos, as mercadorias, o capital passe a ter uma grande mobilidade" (SANTOS, 2005, p. 42). Tal meio técnico-científico-informacional seria

[...] o terreno de eleição para a manifestação do capitalismo maduro, e este também dispõe de força para criá-lo. São duas faces de uma mesma moeda. Por isso, esse meio técnico-científico geografiza-se de forma diferencial, isto é, de forma contínua em algumas áreas contínuas já mencionadas, e de modo disperso no resto do país. A tendência, porém, em todos os casos, é a conquista, relativamente rápida, de mais áreas para o meio técnico científico, ao contrário do meio técnico, que o precedeu como forma geográfica e difundia-se de forma relativamente lenta a certamente mais seletiva. (SANTOS, 2005, p. 43).

Outra perspectiva a ser destacada neste contexto está na constante busca por parte do e-consumidor por agilidade logística na concretização de sua compra. Neste sentido, o que temos acompanhado em nossas observações sobre 0 mercado, é uma busca por parte das grandes e pequenas empresas em suprirem esta demanda, não somente pela instalação de novos Centros de Distribuição como 
acontece nas grandes empresas como o Atacadista Martins, Magazine Luíza e outras nos setores de Atacado e Varejo, mas por conta do empreendedorismo de pequenas empresas ligadas ao comércio eletrônico, que são o resultado de estudos de potencialidades regionais na relação de oferta e demanda, melhores incentivos espaciais com relação à tributação urbana e melhor atendimento logístico, tanto para o consumidor localizado nestes pequenos municípios, como também fornecendo insumos para os pequenos negócios presentes na cidade.

A loja ligada ao setor de vestuário nas pequenas cidades tem por característica geral a venda por multimarcas, pois sua demanda por parte dos consumidores locais é pequena para com cada marca ofertada pela mesma. Assim, a presença de grandes franquias nas pequenas cidades não é uma característica comum à mesma. Neste sentido, estas lojas multimarcas são por muitas vezes atendidas por fornecedores diretos, ou por compras feitas pela internet.

O B2B (Business-To-Business), ramo do comércio eletrônico que caracteriza pela relação entre empresas por meio de comercialização de produtos e insumos para a produção, ou a relação de pequenos empreendedores de um mesmo ramo ligados por uma franquia, como é o caso da relação de pequenos supermercadistas ligados pela Rede Smart de Supermercados, do Grupo Martins.

No enfoque de aquisições e fusões, os grandes grupos atacadistas estão investindo no setor varejista, a exemplo do grupo Martins, de Uberlândia (MG) que durante 50 anos de história investiu em suas atividades atacadistas e, nos últimos 5 anos, construiu uma rede varejista com mais de 600 lojas de supermercados de pequeno porte - a rede Smart. A atuação do grupo no setor de atacado e varejo fornece, hoje, informação para si mesmo, graças ao pleno controle de estoque, pois existe a tecnologia entre seus pares. Esta tecnologia de informação implantada na rede permite com que $\mathrm{o}$ atacadista tenha uma maior eficiência logística e conhecimento sobre o perfil de consumo ligado principalmente às pequenas cidades em que a rede está presente.

Ao analisarmos o caso de grandes grupos corporativos a exemplo do Martins, é importante estabelecer conexões com uma ideia maior. Portanto, ao analisarmos o apontamento de CHANDLER (1988, p. 264) sobre a empresa multiunitária, podemos enxergar os casos empresariais brasileiros, como os varejistas trabalhados antes: 
distribuição, transporte e financiamentos em lugares dispersos e, não raro, em diferentes setores industriais. Sua hierarquia gerencial exerce suas funções primordiais mediante uma estrutura organizacional e um sistema de controle determinados. A moderna empresa, como antes definida, surgiu e prosperou nos setores da economia nos quais pôde coordenar as unidades produtivas mais eficientemente do que os mecanismos de mercado, reduzindo os custos unitários e aumentando a produtividade.

Assim, o campo de trabalho para setor o administrativo torna-se fundamental, pois a concorrência entre os grandes grupos é um jogo de mercado que somente pode ser vencido com bons estrategistas. A ideia de multiunitárismos de Chandler (1988) está vinculada diretamente com o domínio de mercado através do escopo, que somente se torna possível pela marca consolidada. Para o consumidor, a relação estipulada entre a marca e sua qualidade correspondente é o que dá segurança ou não na hora da compra pela internet e o que garante a qualidade de atendimento e das mercadorias oferecidas por uma mesma rede, desde grupos com cinco hipermercados até aqueles com mais de mil filiados, como a rede Smart.

Cabe ainda salientar que esta perspectiva ligada à moderna empresa, concretizada tecnologicamente pelas relações dadas por meio do B2B, influenciam as pequenas cidades por conta de fornecimento de insumos tanto na parte agrícola como pequenas produções específicas. Ainda na perspectiva do comércio eletrônico, ainda podemos destacar o crescente mercado gerado pelos Marketpleces, ao exemplo da Empresa Elo7, que consiste em um portal eletrônico que estabelece a relação comercial entre artesãos de todo o país, contando com mais oito milhões de artesãos que fornecem seus produtos por meio deste portal, e que teve um crescimento de $127 \%$ no ano de 2015 , levando esta empresa a buscar mercado em países da América Latina como a Argentina e o Uruguai. Umas significativas parcelas destes artesãos residem e têm seus negócios nas pequenas cidades.

Consideremos o paralelo que CHANDLER (1988, p. 260) traça entre o desenvolvimento tecnológico e a mudança no quadro empresarial, em que:

[...] essas diferenças podem ser consideradas variações de um mesmo tema. A mão visível da gerência substituiu a mão invisível das forças de mercado onde e quando a nova tecnologia e o crescimento dos mercados possibilitaram um volume e uma rapidez sem precedentes no fluxo de materiais através dos processos de produção e distribuição. A moderna empresa comercial foi, portanto, a reação institucional à rapidez do progresso tecnológico e ao incremento da demanda do consumidor nos Estados Unidos na segunda metade do século XIX. 
Aqui consideramos o comércio eletrônico uma inovação, sobretudo administrativa no setor de vendas e é trabalhado segundo conceitos administrativos como inovação na relação entre comerciante e cliente. Essa inovação pode ser vista em duas faces: o e-commerce e o e-business.

O termo e-commerce representa o modo de compra realizado entre pessoa física e pessoa jurídica (consumidor-loja). Nessa área do comércio eletrônico, as lojas ou empresas que investiram na internet têm, na maioria dos casos, a divisão entre loja "presencial" e loja "virtual". Ambas apresentam o mesmo escopo de produtos e serviços, mas o que destacamos aqui é que a disponibilização de produtos pela internet cria uma gama de consumidores que pode estar localizada em qualquer lugar do território e - por que não? - do globo. Essa possibilidade exige das empresas uma alocação estratégica de centros de distribuição que não mais obedecem só à lógica de localização pelas lojas presenciais. Dentre esses setores do varejo, que disponibiliza os diversos produtos e serviços comercializados na internet, podemos citar o exemplo do setor de lojas de departamentos (Casas Bahia, Ponto Frio, Americanas, Magazine Luiza e outras).

A segunda face do comércio eletrônico - o e-business - caracteriza-se por ser a realização comercial entre empresas, ou seja, entre pessoas jurídicas. Segundo alguns autores da área de administração que tratam do assunto, a evolução do e-commerce é o e-business. O e-business como evolução da perspectiva comercial é à base do arranjo empresarial e de comunicação que coordena a rede de negócios. Se considerarmos o e-business como terceira fase de crescimento do comércio eletrônico, então podemos vê-lo da seguinte maneira:

Chamamos esta fase de e-business, e ela inclui todas as aplicações e os processos que permitem a uma empresa realizar uma transação de negócios. Além de englobar o comércio eletrônico, o e-business inclui atividades de contato e de retaguarda que formam o mecanismo principal do negócio moderno. Assim, o E-business não trata apenas de transações de comércio eletrônico ou de compras e vendas pela internet. É uma estratégia global de redefinição dos antigos modelos de negócios, com o auxílio de tecnologia, para maximizar o valor do cliente e dos lucros. (ROBISON; KALAKOTA, 2002, p. 24).

Ao mesmo tempo, ainda nessa perspectiva de locação, de controle e de comunicação entre os fixos da rede de negócios, encontramos um cenário rico nos estudos das dinâmicas empresariais respaldadas pela sua transformação estrutural da economia, como salientado antes, e a plena realização de sua lógica espacial de 
dinamização da produção. No estudo dessa face do comércio eletrônico, algumas indagações se fazem presentes: como as corporações trabalham com seu estoque, uma vez que possuem sua rede de lojas? Como está espacializada a rede logística? Como funciona sua rede de distribuição de produtos, visto que o consumidor está em qualquer parte do território nacional (ou do mundo, para alguns produtos)? Quais são as dificuldades e soluções para suprir a desigualdade quantitativa de tempo na relação entre venda e entrega? Quais são as estratégias de marketing utilizadas por estas empresas para o estímulo do consumo on-line? E as empresas estabelecem apenas o contato entre consumidores, através dos leilões on-line ante essas corporações? Por outro lado, criamos a principal indagação no que concerne à relação entre comércio e indústria: qual face tem mais peso sobre a outra? Quem induz quem? Qual é a complexidade existente ao longo da cadeia produtiva?

A partir dessas indagações, realizamos um diálogo entre o comércio eletrônico (suas variadas faces) e o cenário empresarial atual na perspectiva macroeconômica a fim de interpretar a organização espacial como objeto da geografia.

Neste sentido, entendemos que as empresas que realizam negócios por meio de uma página eletrônica está em todos os lugares possíveis em que o consumidor consegue ter acesso a esta pagina eletrônica, e desta forma o alcance pode se tornar global, se todos as barreiras de linguagem não forem consideradas, tanto por parte do consumidor que pode estar localizado em um pequeno município, mas que não encontra barreiras com a língua apresentada pela página eletrônica, como por parte da empresa que hoje tem disponível diversos tradutores automáticos para sua página eletrônica.

Assim, a presença da empresa em questão não requer estrutura física para que a mesma possa realizar a mercadoria, e neste ponto da discussão, alguns autores não comungam da ideia que a "presença" da empresa é apenas mensurada apenas pelo consumo, pois apontam que a mercadoria realizada será entregue ao consumidor por estruturas físicas existentes (que vem sendo constantemente inovadas e com cada vez mais concorrentes). No entanto, consideramos aqui que a mercadoria já foi realizada pelo meio eletrônico, e que a denominada entrega ao consumidor se dará por meio de outras empresas, sejam estatais ou privadas.

Deste modo, nesta concepção, o que podemos avaliar sob a ótica da ciência geográfica, é a "disputa" entre diferentes empresas no cenário virtual em um 
"espaço" virtual para venderem suas mercadorias à consumidores localizados em qualquer parte do globo que tenha acesso à internet e uma mínima logística necessária. Assim, os estudos sobre a organização dos estabelecimentos comerciais nas pequenas cidades, por exemplo, são diretamente afetados, tendo em vista que muitos dos pequenos estabelecimentos presentes no município em questão, não vendem tantas mercadorias, como o volume de mercadorias que chega diariamente pelo correio e outras empresas logísticas para um consumidor que possuí uma "janela" muito mais ampla para o mercado brasileiro e internacional.

\section{Considerações Finais}

Nesse sentido, ao realizarmos uma pesquisa sobre o comércio eletrônico, remetemos essa perspectiva ao entendimento das transformações do comércio de forma a apresentar-se em diferentes faces. O consumo pela internet, para o caso brasileiro, ainda não se tornou realidade: os dados são "tímidos"; mas encontra-se em plena fase de expansão, como mostram os dados anteriormente apresentados. No entanto, sua realização social, ou ao que podemos atribuir ao papel da plena "fetichização" da mercadoria, apresenta-se de forma considerável em razão de "marcas" já consolidadas no mercado e que subsidiam o padrão de consumo dos produtos negociados pela internet. O exemplo mais claro dessa afirmativa está no consumo e na certeza - atribuída pelo consenso popular - de que a compra de produtos eletrônicos tem mais garantia quando associada a marcas como Sony, Phillips, Panasonic e outras.

Dessa maneira, seguindo o desenvolvimento histórico do circuito do capital, o comércio eletrônico dinamiza o principal fator na articulação do comércio com a produção: a informação. À medida que compramos produtos pela internet, estamos fornecendo aos agentes comerciais a informação sobre nossas preferências de consumo através de cadastros e registros em newsletters (informativos dos websites de compra). O banco de dados construído através desse ferramental técnico fornece, ao comércio, meios de negociar com a produção mais precisa. Uma vez que o circuito do capital é, de certa maneira, invertido quando compramos um produto em websites que oferecem mercadorias — ainda não produzidas — , isso cria certa pressão sobre a indústria; afinal, esta precisa produzir um produto já pago e realizado, segundo a perspectiva de Karl Marx, pelo comércio através do pagamento com cartão magnético (meio que retém a informação de consumo), de 
modo que o consumidor o receba o quanto antes graças a um trabalho logístico seguindo a política do just-in-time, que fideliza o consumidor ao agente comercial (website). O avanço das tecnologias de comunicação possibilitou à moderna empresa ser mais bem caracterizada, a investir no aumento de escopo e, logo, a conduzir um processo de crescimento horizontal, dando nova dinâmica ao dito espaço geográfico.

Com o aumento da população brasileira (sobretudo a urbana), a cidade se torna o grande obstáculo para a perfeição da entrega das mercadorias adquiridas por meio do comércio eletrônico; ao mesmo tempo, suas intempéries transformaramse no principal motivador para que classes médias e grupos de alta renda explorassem o comércio eletrônico em uma escala intraurbana. O consumidor em um município pequeno busca, através das páginas eletrônicas de grandes lojas, adquirir produtos que o comércio local não oferece, influenciando-o através da concorrência. Os produtos comercializados nessa última perspectiva incluem: livros, CDs, eletroeletrônicos e outros.

Esse entendimento do comércio eletrônico associado com transformações recentes na lógica empresarial - logo, macroeconômica - e numa análise à luz da ciência geográfica cria uma leitura das empresas e de sua organização espacial que se insere na relação entre sociedade e natureza pela dinâmica do meio técnicocientífico-informacional, seja no espaço geográfico tradicional ou no "e-espaço".

\section{REFERÊNCIAS}

CÂMARA BRASILEIRA COMÉRCIO ELETRÔNICO/CBCE. Disponível em: https://www.camara-e.net/- acessado em março de 2019.

CARVALHO, Marcelo Sávio Revoredo Menezes de. A trajetória da Internet no Brasil: do surgimento das redes de computadores à instituição dos mecanismos de governança. 2006, 239 p. Dissertação. COPPE/UFRJ, M.Sc., Engenharia de Sistemas e Computação Universidade Federal do Rio de Janeiro, COPPE

CASTELLS, Manuel. A galáxia da internet: reflexões sobre a internet, os negócios e a sociedade. Rio de Janeiro: Jorge Zahar, 2003.

CHANDLER, Alfred. Ensaios para a teoria da grande empresa. Rio de Janeiro: editora da Fundação Getúlio Vargas, 1998.

CRONIN, Mary. Fazendo “business” via internet. São Paulo: Erika, 2005. 
DRUCKER, Peter. A revolução do comércio eletrônico. In: JULIO, Carlos Alberto; SALIBIU NETO, José. E-business e tecnologia: autores e conceitos imprescindíveis. São Paulo: Publifolha, 2001, p. 90-107.

E-BIT / BUSCAPÉ. Disponível em: https://www.ebit.com.br/- acessado em março de 2016. MARX, Karl. Contribuição à crítica da economia política. 3. ed. São Paulo: Martins Fontes, 2003. 405 p.

MAYO, A.; NOHRIA, N. Da crise do petróleo à internet - série "O mundo dos negócios e seus ícones". São Paulo: Campus, 2008.

NAKAWAGA, Sandra S. Y. A lealdade dos consumidores nos ambientes de comércio online e offline. 2008. 310p. Tese (Doutorado em Administração de Empresa) — Faculdade de Economia, Administração e Contabilidade da Universidade de São Paulo, São Paulo.

RELATÓRIO WEBSHOPPERS ebit [online]. Edição 35. Relatório sobre o Comércio Eletrônico em 2016. Disponível em: https://www.ebit.com.br/webshoppers. Acessado em: maio de 2017. 51p.

RELATÓRIO WEBSHOPPERS ebit [online]. Edição 39. Relatório sobre o Comércio Eletrônico em 2018. Disponível em: https://www.ebit.com.br/webshoppers. Acessado em: março de 2019. 41p.

ROBISON, M.; KALAKOTA, R. E-business: estratégias para alcançar o sucesso no mundo digital. 2. ed. São Paulo: Bookman, 2002.

SANTOS, Milton. A natureza do espaço. São Paulo: editora da Universidade de São Paulo, 2005.

TEZZA, R.; BORNIA, A. C.; HEDLER, F.; GONCALVES, M. B. Impactos do comércio eletrônico na cadeia de suprimentos. In: SIMPÓSIO DE EXCELÊNCIA EM GESTÃO E TECNOLOGIA (SEGET), 5.; SIMPÓSIO DE EXCELÊNCIA EM GESTÃO E TECNOLOGIA (SEGET), 5., Resende: Associação Educacional Dom Bosco, 2008. v. 1.

\section{NOTAS DE AUTOR}

CONTRIBUIÇÃO DE AUTORIA:

Pedro Eduardo Ribeiro de Toledo - Concepção. Coleta de dados, Análise de dados, Elaboração do manuscrito e revisão da versão final do trabalho

FINANCIAMENTO

Não se aplica.

CONSENTIMENTO DE USO DE IMAGEM

Não se aplica.

APROVAÇÃO DE COMITÊ DE ÉTICA EM PESQUISA

Não se aplica.

CONFLITO DE INTERESSES

Não se aplica. 


\section{LICENÇA DE USO}

Este artigo está licenciado sob a Licença Creative Commons CC-BY. Com essa licença você pode compartilhar, adaptar, criar para qualquer fim, desde que atribua a autoria da obra.

\section{HISTÓRICO}

Recebido em: 08-04-2019

Aprovado em: 28-05-2020 